\title{
Effects of infinitely fast chemistry on combustion behavior of coaxial diffusion flame predicted by large eddy simulation
}

\author{
Shota Akaotsu ${ }^{\mathrm{a}, *}$, Ryoma Ozawa $^{\mathrm{a}}$, Yohsuke Matsushita ${ }^{\mathrm{a}}$, Hideyuki Aoki ${ }^{\mathrm{a}}$, \\ Weeratunge Malalasekera ${ }^{b}$ \\ ${ }^{a}$ Department of Chemical Engineering, Graduate School of Engineering, Tohoku University, \\ 6-6-07 Aoba, Aramaki, Aoba-ku, Sendai, Miyagi, 980-8579, Japan \\ ${ }^{b}$ School of Mechanical, Electrical and Manufacturing Engineering, Loughborough University, \\ Loughborough LE11 3TU, UK
}

\begin{abstract}
Large eddy simulations (LES) based on turbulent combustion models aid the design and optimization of combustors. Of the various combustion models available, the eddy break up (EBU) model is widely used because it assumes an infinitely fast chemistry. However, omitting the actual chemical kinetics can cause unexpected behavior, and the characteristics of the combustion models need to be elucidated. Here, the effects of an infinitely fast chemistry on the combustion behavior of a coaxial diffusion flame as predicted by an LES were analyzed. Although the EBU model captured the overall behavior of the chemical species as well as the flow field, the gas temperature and mass fractions of the combustion products in the mixing region of the fuel and oxidizer streams were overestimated. In contrast, the flamelet/progress variable (FPV) model yielded results that were in better agreement with the experimental data, because while the EBU model assumes an infinitely fast chemistry, the look-up tables used in the FPV model are based on the actual chemical kinetics. As these models can be used for the CFD simulations of coal and spray combustion, the results of this study should be useful for efficiently simulating practical combustion systems. Keywords: large eddy simulation, combustion, eddy break up model,
\end{abstract}

\footnotetext{
* Corresponding author

Email address: akaotsu@dc.tohoku.ac.jp (Shota Akaotsu)
}

Preprint submitted to Journal of ${ }^{A} T_{E} X$ Templates

September 21, 2019 
flamelet/progress variable model, flame structure

\section{Introduction}

Advanced combustion technologies, such as flameless oxidation (also termed moderate or intense low oxygen dilution (MILD) combustion) [I-B], ammonia

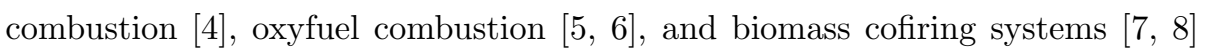
5 for the combustion of pulverized coal have been developed to achieve sustainable and high-efficiency energy production [9-14]. The contribution of numerical simulations to the development of these technologies is now comparable to that of experiments because of the significant increases in computing performance in recent years. For instance, simulation-based studies have made major contributions to current efforts to reduce NOx and soot formation within combustors [ [15-[18]. For instance, Enagi et al. used computational fluid dynamics (CFD) simulations to design and optimize the combustion chamber of a micro gas turbine and succeeded in developing a combustion system with a low inlet temperature and low emissions [1.9]. Further, the synergetic effects of a system combining MILD combustion and oxyfuel combustion, namely, an oxy-MILD system, were assessed by Perrone et al. using CFD simulations [20]. Using these simulations, they were able to study the mechanism of $\mathrm{NO}_{\mathrm{x}}$ reduction and determine how to ensure a uniform heat flux. One of the most important factors in combustion simulations is the method used to model the chemical reactions.

${ }_{20}$ As nearly all practical combustion devices experience turbulence, the chemical reactions are often modeled using the large eddy simulation (LES) method or the Reynolds-averaged Navier-Stokes (RANS) equation.

In combustion simulations performed using the LES method, which has been used extensively in recent years, the Favre filter used with the govern25 ing equations, including the conservation equations for the chemical species, and the physical quantities are divided into grid-scale (GS) and subgrid-scale (SGS) components. Further, the source terms in the transport equations of the chemical species are also averaged through filtering operations. Because of 
the presence of the exponential temperature term in the Arrhenius form of the equation for the chemical reaction rate, the exact value of the averaged chemical reaction rate cannot be estimated directly from the average temperature $[21,[22]$. To overcome this problem, researchers have proposed various turbulent combustion models.

Spalding suggested that combustion occurs during the collapsing of the (EBU) model, which uses the reactedness as an indicator of the progress of the chemical reactions, and was able to determine the timescale of the eddies [U]]. Further, using a similar concept, Magnussen and Hjertager developed the eddy dissipation (ED) model, which calculates the timescale of the chemical reactions 40 based on the dissipation rate of the turbulence energy [23]. Although this model was originally developed for RANS-based simulations, it can also be used with the LES method if one changes the expression for the timescale of the eddies $[24,[25]$. The above-described models assume an infinitely fast chemistry to simplify the modeling of the interactions between the turbulence and the chemical 45 reactions. Moreover, as an infinitely fast chemistry allows for the closure of the reaction source term, these models can be used in various scenarios, including for multiphase combustion, without any modifications. Desjardin and Frankel extended the idea of scale similarity to evaluate the SGS components of the chemical reactions involved in combustion and developed the scale similarityfiltered reaction rate model (SSFRRM) [26]. In this model, the overall reaction rate is calculated as the sum of the resolved and unresolved components of the reaction rate. The unresolved parts are estimated from the twice-filtered reaction rate and the model parameters while the resolved parts are evaluated directly in the Arrhenius form using the filtered variables. Although some ambiguity remains with respect to the model parameters, the SSFRRM has been used successfully to model the combustion of pulverized coal [27] because an infinitely fast chemistry is not assumed in this case.

Flamelet-based tabulated chemistry methods are also attractive for accounting for the finite chemistry during turbulence. Of the various combustion 
models that have been proposed based on tabulated chemistry, the flamelet/progress variable $(\mathrm{FPV})$ model [르] and the flamelet-generated manifolds (FGM) model $[29,30]$ are notable examples. In these models, it is assumed that the chemical reactions are much faster than the fluid motion, and the calculations related to the chemical reactions are performed separately from the fluid simulations.

${ }_{65}$ Further, look-up tables are generated by simulating a simple one-dimensional flame before the fluid simulations. When the target flow field includes the turbulence, the Favre-averaged variables can be stored by assuming the shape of the subgrid-scale probability density function (PDF) instead of using instantaneous variables[3]]. Flamelet-based tabulated chemistry methods have been extended to spray [32, 3:3] and pulverized coal combustion [34, 35] by adjusting the controlling parameters and the dimensions of the look-up table.

On the other hand, there is still a strong demand for " reasonable" combustion models such as the EBU and ED models in the industry. For examples, the look-up tables that are used in tabulated chemistry models must be reconstructed when the boundary conditions of the target device change. In addition, tabulated chemistry models cannot handle multicomponent fuel with ease, because the number of representative variables is limited. Otherwise, a very large number of precalculations must be performed to construct the multidimensional look-up tables. In fact, coal combustion involves the combustion of a large so number of different fuel streams, and the use of tabulated chemistry methods becomes challenging. Given this background, combustion models based on an infinitely fast chemistry and global chemical reactions are still popular in the industry and are being used in LES-based studies [36-38].

The main objective of this study was to describe the features of various combustion models and provide insights for ensuring reasonable simulations of the combustion process. The EBU and FPV models were taken as the representative simulation models for the LES of a coaxial diffusion flame. The rest of the manuscript is divided as follows. First, the target domain and numerical conditions, including the governing equations, are described. Next, the underlying principles of the combustion models are explained. In particular, 
the procedure for constructing the look-up tables is described in detail. In the Results and Discussion section, the numerical results obtained using the EBU and FPV models are compared in order to elucidate the effects of an infinitely fast chemistry on the combustion behavior.

\section{Large eddy simulation (LES) of coaxial diffusion flames}

\subsection{Computational domain and numerical conditions}

The computational domain in this study was a combustor in which a CH4/air coaxial diffusion flame is formed at a pressure of $3.8 \mathrm{~atm}$ [39, 40]. A schematic

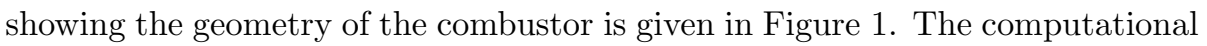
region was the same as that used in a previous study [ㅍ] and was divided into approximately 1.8 million cells. The numerical conditions used are summarized

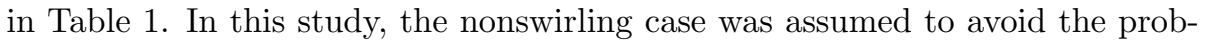
lem of the inlet conditions. A double pipe was placed on the left side of the computational domain, and $\mathrm{CH}_{4}$ and preheated air were supplied at average velocities of $0.9287 \mathrm{~m} / \mathrm{s}$ and $20.63 \mathrm{~m} / \mathrm{s}$, respectively. With respect to the inlet boundary conditions, a power-law profile was used for the fuel stream, which was provided from the inner or center pipe, while a uniform profile was used for the oxidizer stream. Note that no fluctuations were added to the inlet velocity profile in this study because it is difficult to generate physically "valid" turbulence fluctuations which satisfy the target turbulent statistics. The main objective of this study was to point out the difference between the EBU model and the FPV model as described in the introduction. In terms of this objective, the most important point is to impose the same inlet conditions to both cases and the existence of turbulent fluctuation is not a critical issue in this study. In addition, a velocity difference of the two jets primarily contributed to the generation of the fluctuations near the inlet boundary, and the effect of fluctuations at the inlet plane would be small enough to be ignored in the target domain. The wall function proposed by Werner and Wengle [41] was adopted for the wall, while the outflow boundary conditions used by Matsushita [42] were imposed 
at the exit plane.

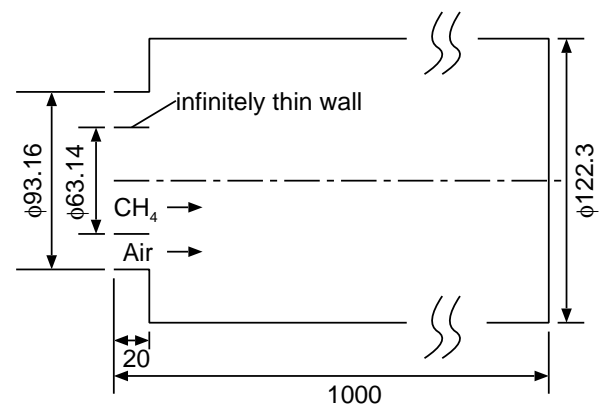

Figure 1: Detailed geometry of computational domain.

Table 1: Numerical conditions used in this study.

\begin{tabular}{lcc}
\hline Inlet velocity of fuel (from center pipe) & {$[\mathrm{m} / \mathrm{s}]$} & 0.9287 \\
Inlet velocity of oxidant (from annular pipe) & {$[\mathrm{m} / \mathrm{s}]$} & 20.63 \\
Temperature of fuel & {$[\mathrm{K}]$} & 300 \\
Temperature of air & {$[\mathrm{K}]$} & 750 \\
Ambient pressure & {$[\mathrm{atm}]$} & 3.8 \\
\hline
\end{tabular}

\subsection{Computational domain and numerical conditions}

As stated in the Introduction section, the LES was performed using two turbulent combustion models, namely, the EBU and FPV models. The governing equations in the case of the EBU model were the Favre-filtered transport equations for the mass, momentum, energy, and species mass fraction, as follows:

$$
\begin{gathered}
\frac{\partial \bar{\rho}}{\partial t}+\frac{\partial}{\partial x_{j}}\left(\bar{\rho} \widetilde{u}_{j}\right)=0 \\
\frac{\partial}{\partial t}\left(\bar{\rho} \widetilde{u}_{i}\right)+\frac{\partial}{\partial x_{j}}\left(\bar{\rho} \widetilde{u}_{i} \widetilde{u}_{j}\right)+\frac{\partial}{\partial x_{j}}\left\{\bar{\rho}\left(\widetilde{u_{i} u_{j}}-\widetilde{u}_{i} \widetilde{u}_{j}\right)\right\} \\
=-\frac{\partial \bar{p}}{\partial x_{i}}+\frac{\partial}{\partial x_{j}}\left[\widetilde{\mu}\left(\frac{\partial \widetilde{u}_{i}}{\partial x_{j}}+\frac{\partial \widetilde{u}_{j}}{\partial x_{i}}-\frac{2}{3} \delta_{i j} \frac{\partial \widetilde{u}_{k}}{\partial x_{k}}\right)\right] \\
\frac{\partial}{\partial t}(\bar{\rho} \widetilde{h})+\frac{\partial}{\partial x_{j}}\left(\bar{\rho} \widetilde{u}_{j} \widetilde{h}\right)+\frac{\partial}{\partial x_{j}}\left\{\bar{\rho}\left(\widetilde{h u_{j}}-\widetilde{h} \widetilde{u}_{j}\right)\right\}=\frac{\partial}{\partial x_{j}}\left(\frac{\widetilde{\mu}}{\sigma_{h}} \frac{\partial \widetilde{h}}{\partial x_{j}}\right)
\end{gathered}
$$




$$
\frac{\partial}{\partial t}\left(\bar{\rho} \widetilde{Y}_{k}\right)+\frac{\partial}{\partial x_{j}}\left(\bar{\rho} \widetilde{u}_{j} \widetilde{Y}_{k}\right)+\frac{\partial}{\partial x_{j}}\left\{\bar{\rho}\left(\widetilde{Y_{k} u_{j}}-\widetilde{Y}_{k} \widetilde{u}_{j}\right)\right\}=\frac{\partial}{\partial x_{j}}\left(\frac{\widetilde{\mu}}{\sigma_{y}} \frac{\partial \widetilde{Y}_{k}}{\partial x_{j}}\right)+\overline{\dot{\omega}}_{k}
$$

where $\widetilde{u}_{i}$ and $\bar{\rho}$ are the Favre-filtered velocity and spatially filtered density, which was calculated from the ideal gas law. Moreover, $\bar{p}$ and $\widetilde{\mu}$ denote the spatially filtered pressure and Favre-filtered molecular viscosity, respectively, while $\widetilde{h}$ and $\sigma_{h}$ are the Favre-filtered enthalpy and the laminar Prandtl numbers, respectively. In keeping with previous work [26], radiation was not considered because the classical FPV model cannot consider any "external" effects except for chemical reactions. $\widetilde{Y}_{k}, \sigma_{y}, \overline{\dot{\omega}}_{k}$ are the Favre-filtered mass fraction of the chemical species, laminar Schmidt number, and spatially filtered net production rate of the chemical species. In this study, $\sigma_{h}$ and $\sigma_{y}$ were kept constant at 0.7. The third term of a left hand side in Eq. (『) is SGS turbulent momentum flux, and the anisotropic part was numerically approximated from the following term:

$$
\begin{array}{r}
-\bar{\rho}\left(\widetilde{u_{i} u_{j}}-\widetilde{u}_{i} \widetilde{u}_{j}\right)-\frac{1}{3} \bar{\rho}\left(\widetilde{u_{k} u_{k}}-\widetilde{u}_{k} \widetilde{u}_{k}\right) \delta_{i j} \\
\simeq \mu_{t}\left(\frac{\partial \widetilde{u}_{i}}{\partial x_{j}}+\frac{\partial \widetilde{u}_{j}}{\partial x_{i}}-\frac{2}{3} \delta_{i j} \frac{\partial \widetilde{u}_{k}}{\partial x_{k}}\right),
\end{array}
$$

where $\mu_{t}$ and $\delta_{i j}$ are turbulent viscosity and Kronecker delta. The isotropic part of the SGS turbulent momentum flux, which is the second term in Eq. (氤), was included in the pressure gradient term in Eq.(Z) . In a similar way, the SGS turbulent energy and scalar fluxes, which corresponds to the third terms in Eqs. (ㅍ) and (四) were also numerically approximated from the following terms:

$$
\begin{gathered}
-\bar{\rho}\left(\widetilde{h u_{j}}-\widetilde{h} \widetilde{u}_{j}\right) \simeq \frac{\mu_{t}}{\sigma_{h t}} \frac{\partial \widetilde{h}}{\partial x_{j}}, \\
-\bar{\rho}\left(\widetilde{Y_{k} u_{j}}-\widetilde{Y}_{k} \widetilde{u}_{j}\right) \simeq \frac{\mu_{t}}{\sigma_{y t}} \frac{\partial \widetilde{Y}_{k}}{\partial x_{j}},
\end{gathered}
$$

where $\sigma_{h t}$ and $\sigma_{y t}$ denote turbulent Prandtl and Schmidt number, which were assigned to values of 0.7 and 0.4 , respectively.

In the FPV model, the equations for the enthalpy and the transport of the chemical species do not have to be solved because all the thermochemical parameters such as the fluid density and viscosity are retrieved from the look-up 
tables using the mixture fraction and progress variable. Thus, instead of the equations for the enthalpy and the transport of the chemical species, those for the mixture fraction and progress variable must be solved:

$$
\frac{\partial}{\partial t}(\bar{\rho} \widetilde{Z})+\frac{\partial}{\partial x_{j}}\left(\bar{\rho} \widetilde{u}_{j} \widetilde{Z}\right)+\frac{\partial}{\partial x_{j}}\left\{\bar{\rho}\left(\widetilde{Z u_{j}}-\widetilde{Z} \widetilde{u}_{j}\right)\right\}=\frac{\partial}{\partial x_{j}}\left(\frac{\widetilde{\mu}}{\sigma_{y}} \frac{\partial \widetilde{Z}}{\partial x_{j}}\right),
$$

150

$$
\begin{aligned}
\frac{\partial}{\partial t}\left(\bar{\rho} \widetilde{Y}_{p v}\right)+\frac{\partial}{\partial x_{j}}\left(\bar{\rho} \widetilde{u}_{j} \widetilde{Y}_{p v}\right) & +\frac{\partial}{\partial x_{j}}\left\{\bar{\rho}\left(\widetilde{Y_{p v} u_{j}}-\widetilde{Y}_{p v} \widetilde{u}_{j}\right)\right\} \\
& =\frac{\partial}{\partial x_{j}}\left(\frac{\widetilde{\mu}}{\sigma_{y}} \frac{\partial \widetilde{Y}_{p v}}{\partial x_{j}}\right)+\overline{\dot{\omega}}_{p v} .
\end{aligned}
$$

Here, $\widetilde{Z}$ is the Favre-filtered mixture fraction. Further, $\widetilde{Y}_{p v}$ and $\overline{\dot{\omega}}_{p v}$ are the Favre-filtered progress variable and spatially filtered source term of the progress variable, respectively. The SGS turbulent scalar fluxes were numerically approximated from the following terms:

$$
-\bar{\rho}\left(\widetilde{Z u_{j}}-\widetilde{Z} \widetilde{u}_{j}\right) \simeq \frac{\mu_{t}}{\sigma_{y t}} \frac{\partial \widetilde{Z}}{\partial x_{j}},
$$

155

$$
-\bar{\rho}\left(\widetilde{Y_{p v} u_{j}}-\widetilde{Y}_{p v} \widetilde{u}_{j}\right) \simeq \frac{\mu_{t}}{\sigma_{y t}} \frac{\partial \widetilde{Y}_{p v}}{\partial x_{j}},
$$

The eddy viscosity coefficient was calculated using the dynamic Smagorinsky model [4.3]. In this study, the PDF was presumed and the shape of the PDF was determined beforehand, that is, the $\beta$-function was used to determine the shape of the PDF for the mixture fraction. The SGS variance of the mixture fraction was evaluated using the algebraic method proposed by Branley and Jones [44]:

$$
\widetilde{Z^{\prime \prime 2}}=C_{z} \Delta^{2}\left(\frac{\partial \widetilde{Z}}{\partial x_{j}}\right)^{2}
$$

where $C_{z}$ and $\Delta$ are a model coefficient $(=0.1[44])$ and a filter width, which is determined by the volume of the computational cell with $V_{\text {cell }}^{1 / 3}$. The effect of the SGS variance of the progress variable was ignored by assuming that the shape of the PDF could be represented by the $\delta$-function. Although the SGS variance of the progress variable has a significant effect on calculations performed for limited domains [45-47], the effect should be small in the case of a stable flame, as was the case in the investigated domain. 


\subsection{Modeling of turbulent combustion}

\subsubsection{Eddy break up (EBU) model for LES (from [24])}

Generally, combustion occurs when the fuel and oxidant come in contact with a diffusion flame. The rate of combustion can be estimated from the mixing rate of the fuel and oxidant when the chemical reaction rate based on the reaction kinetics is much higher than the mixing rate. In the EBU model proposed by $\mathrm{Hu}$ et al. [24], the rate of combustion is represented by the following equations:

$$
\begin{gathered}
\overline{\dot{\omega}}_{\mathrm{fu}}=c_{1} \bar{\rho}|\bar{S}| \min \left(\widetilde{Y}_{\mathrm{fu}}, \frac{\widetilde{Y}_{\mathrm{ox}}}{s}, c_{2} \frac{\widetilde{Y}_{\mathrm{pr}}}{1+s}\right), \\
|\bar{S}|=\sqrt{\widetilde{S}_{i j} \widetilde{S}_{i j}}, \\
\widetilde{S}_{i j}=\frac{1}{2}\left(\frac{\partial \widetilde{u}_{i}}{\partial x_{j}}+\frac{\partial \widetilde{u}_{j}}{\partial x_{i}}\right)
\end{gathered}
$$

where $c_{1}$ and $c_{2}$ are the model constants, which were fixed at 4.0 and 0.5 , respectively. As shown in Eq.([3]), the timescale of the collapsed eddies is represented by the strain rate tensor. This model is often used in the LES of pulverized coal combustion [36-38]. Moreover, $\mathrm{s}$ is the stoichiometric coefficient for the global chemical reaction of $\mathrm{CH}_{4}$, which can be represented as the following one-step reaction:

$$
\mathrm{CH}_{4}+2 \mathrm{O}_{2} \rightarrow \mathrm{CO}_{2}+2 \mathrm{H}_{2} \mathrm{O} \text {. }
$$

Using the above-mentioned global chemical reaction, the transport equations for five chemical species, $\mathrm{CH}_{4}, \mathrm{O}_{2}, \mathrm{CO}_{2}, \mathrm{H}_{2} \mathrm{O}$ and $\mathrm{N}_{2}$, were solved. In this study, a multistep global reaction was possible to be used instead of the onestep global reaction (R1). However, it remains a matter of debate whether the accuracy is improved by increasing the number of reaction steps because the kinetic parameters cannot be considered as long as the EBU model is used; this is irrespective of the number of reaction steps. Thus, it should be noted that the differences in the numerical results obtained using the EBU and FPV models 
are attributable to the effect of an infinitely fast chemistry, as described later, although the differences in the reaction mechanisms in addition to those in the reaction rate also probably affect the numerical results.

To compare the numerical solutions obtained using the EBU and FPV models, the mixture fraction, $\xi$, which was defined by Bilger [48], was calculated using the following equation:

$$
\xi=\frac{2 \frac{Z_{\mathrm{C}}}{W_{\mathrm{C}}}+\frac{Z_{\mathrm{H}}}{W_{\mathrm{H}}}-\frac{2\left(Z_{\mathrm{O}}-Z_{\mathrm{O}, \mathrm{ox}}\right)}{W_{\mathrm{O}}}}{2 \frac{Z_{\mathrm{C}, \mathrm{fu}}}{W_{\mathrm{C}}}+\frac{Z_{\mathrm{H}, \mathrm{fu}}}{W_{\mathrm{H}}}+\frac{2 Z_{\mathrm{O}, \mathrm{ox}}}{W_{\mathrm{O}}}} .
$$

\subsubsection{Flamelet/progress variable (FPV) model (from [28])}

The look-up tables containing information regarding the thermochemical properties were constructed through one-dimensional calculations of a nonpremixed flame prior to the main CFD simulation using the FPV model. Next, the mixture fraction and progress variable were used as the representative parameters. The mixture fraction represents the mixing of the fuel and oxidant and is the conserved variable whereas the combustion process ranging from the unburnt state to the burnt one is described by the progress variable. As the progress variable must increase or decrease monotonically as the chemical reaction progresses, the mass fractions of the primary products are often used to determine the variable $[\underline{Z Z}, 4,4]$. In this study, the progress variable was defined as the sum of the mass fractions of the major products, as follows,

$$
Y_{\mathrm{pv}}=Y_{\mathrm{CO}_{2}}+Y_{\mathrm{CO}}+Y_{\mathrm{H}_{2} \mathrm{O}}+Y_{\mathrm{H}_{2}}
$$

The one-dimensional counterflow diffusion flame was simulated using the GRImech 3.0 mechanism [50] and FlameMaster code [5] , which is a software library for laminar flame calculations. The boundary conditions used were those corresponding to the target experiment, and the steady-state flamelet equations were solved in the mixture fraction space for a specified stoichiometric scalar dissipation rate. Note that the Lewis numbers of all the chemical species were assumed to be unity. The look-up table, which covered a wide range of states 
(from the unstable state to the stable one, including extinction), was generated from the numerical solutions obtained for the various stoichiometric scalar dissipation rates.

Figure $\square$ shows the temperature distributions in the stable branch for various stoichiometric scalar dissipation rates. The maximum temperature decreased with an increase in the stoichiometric scalar dissipation rate. Furthermore, the flame was extinguished at the extinction points. Using the unstable branch, three-dimensional look-up tables were constructed by aligning the calculation data according to the mixture fraction, progress variable, and SGS variance of the mixture fraction. The progress variable was normalized with respect to the maximum and minimum values at each mixture fraction as per a previous study [52-54]. The normalized progress variable was defined by the following equation:

$$
C=\frac{Y_{\mathrm{pv}}-Y_{\mathrm{pv}}^{\min }}{Y_{\mathrm{pv}}^{\max }-Y_{\mathrm{pv}}^{\min }}
$$

In the LES method, the instantaneous variables, which are the raw data for the one-dimensional calculations, have to be converted into the subfiltered variables. When the shapes of the PDFs of the mixture fraction and progress variables are known, the Favre-filtered variables can be obtained from

$$
\widetilde{\phi}=\int_{0}^{1} \int_{0}^{1} \phi(Z, C) \widetilde{P}(Z) \widetilde{P}(C) \mathrm{d} Z \mathrm{~d} C,
$$

where $\widetilde{P}(Z)$ and $\widetilde{P}(C)$ are are the PDFs of the mixture fraction and normalized progress variables, respectively. As shown in Eq. ([7), the PDFs of the mixture fraction and progress variables were described separately because it was assumed in this study that the mixture fraction and progress variables are independent. Further, by assuming the $\delta$-function for the progress variables, $\widetilde{P}(C \mid Z ; \widetilde{C})$ and and the $\beta$-function for the mixture fraction, $\widetilde{P}\left(Z ; \widetilde{Z}, \widetilde{Z^{\prime \prime 2}}\right)$, Eq. (ㅁ) can be written as follows:

$$
\widetilde{\phi}=\int_{0}^{1} \int_{0}^{1} \phi(Z, C) \widetilde{P}\left(Z ; \widetilde{Z}, \widetilde{Z^{\prime \prime 2}}\right) \widetilde{P}(C \mid Z ; \widetilde{C}) \mathrm{d} Z \mathrm{~d} C
$$

where $\widetilde{Z^{\prime \prime 2}}$ denotes the SGS variance of the mixture fraction, which is estimated using subfilter models during CFD simulations. While constructing the look-up 
tables, arbitrary values were assigned to the variance of the mixture fraction to cover the entire estimated range of the variance for the CFD simulation. To simplify the procedure for determining the dimension of the SGS variance, the normalized SGS variance, $\widetilde{Z_{v}}$ which can take values from zero to unity, was introduced. The possible range of the actual SGS variance is restricted by the mean mixture fraction as follows:

$$
0 \leq \widetilde{Z^{\prime \prime 2}} \leq \widetilde{Z}(1-\widetilde{Z})
$$

Under this restriction, the actual SGS variance as estimated by the CFD simulation was linked to the normalized form by

$$
\widetilde{Z_{v}}=\frac{\widetilde{Z^{\prime \prime 2}}}{\widetilde{Z}(1-\widetilde{Z})} .
$$

It should be noted that the progress variable and SGS variance during the LES must undergo a transformation before the look-up procedure because these variables, which were obtained from the transport equation or a subfilter model, are in the non-normalized form. The resolution of the look-up tables was $\widetilde{Z} \times$ $\widetilde{Z_{v}} \times \widetilde{C}=150 \times 20 \times 150$. Here, the final form of all the subfiltered thermal and chemical properties in the look-up tables can be written as follows:

$$
\widetilde{\phi}=\widetilde{\phi}\left(\widetilde{Z}, \widetilde{Z_{v}}, \widetilde{C}\right) .
$$

For example, Figure 3 shows the contour plots of the gas temperature and production rate of the progress variable in the Z-C plane for an SGS variance of zero. The production rate of the progress variable is an important parameter because the progress variable is generated with the production rate stored in the look-up tables while the mixture fraction is a conserved scalar. That is to say, the source term in the transport equations is zero. 


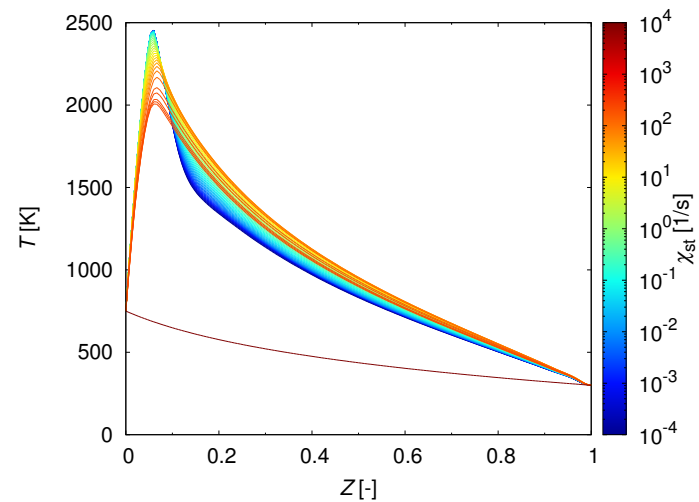

Figure 2: Temperature distributions in stable branch at various stoichiometric scalar dissipation rates. 


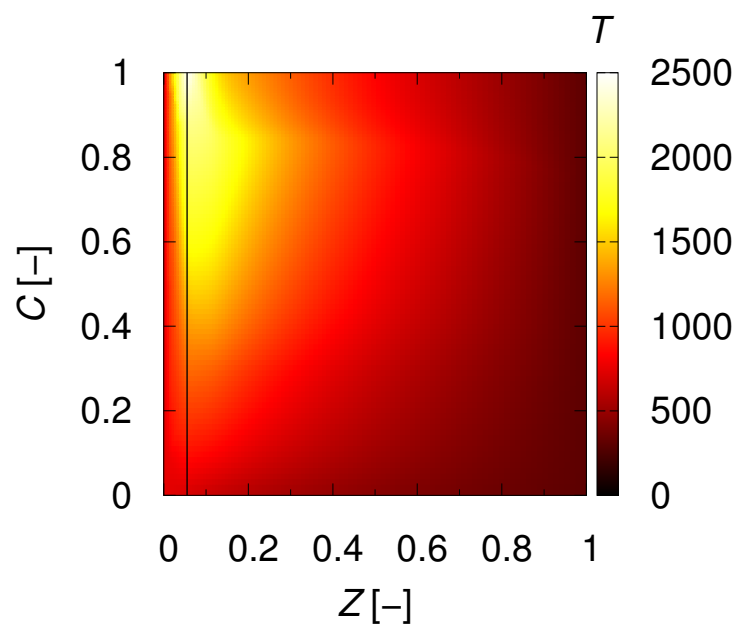

(a) Temperature

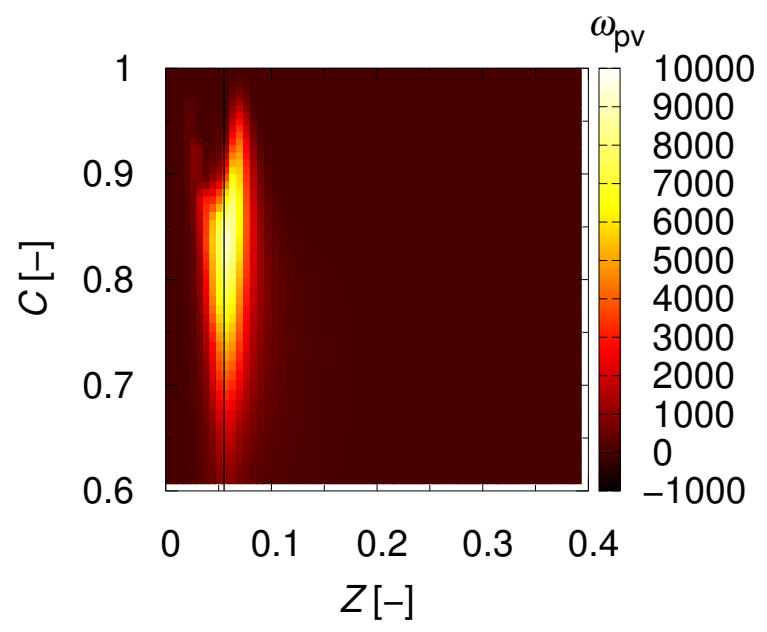

(b) Production rate of progress variable

Figure 3: Contour plots of (a) gas temperature and (b) production rate of progress variable in $Z-C$ plane with SGS variance of zero. Plot of production rate of progress variable corresponds to stoichiometric mixture, $Z_{\text {st }}=0.0552$. 


\subsubsection{Numerical methods}

Code developed in-house based on unstructured grids and the finite volume method [5.5, 56] was used for the CFD simulation. For the time integration of the momentum equations, the Adams-Bashforth method was used, and the convective terms were discretized using the total variational diminishing (TVD) scheme with the min-mod limiter [57]. The same scheme was also used for the convective terms in the transport equations of the chemical species, mixture fraction, and progress variable. The second-order central differencing scheme was used for the discretization of the diffusion terms in all the governing equations. The pressure and velocity were coupled with the simplified marker and cell (SMAC) method [58], and the pressure correction equations were solved using the algebraic multigrid solver (AMGS) [5.9]. The other equations were solved using the bi-conjugate gradient stabilized method with polynomial preconditioning (Bi-CGSTAB) [60]. The timestep was determined by restricting the Courant number to a maximum of 0.3. The simulations were performed on the workstations using 24 cores of Intel ${ }^{\circledR}$ Xeon ${ }^{\circledR}$ Processor X5675. The physical runtime was set to $1.5 \mathrm{~s}$ so that enough data were sampled for statistical analysis. The time-mean values were calculated by instantaneous data obtained in $0.5-1.5 \mathrm{~s}$.

\section{Results and discussion}

\subsection{Gas temperature and mixture fraction}

Figure 9 shows the instantaneous distributions of the temperature along the plane $y=0$. In the EBU model, a high-temperature zone was generated near the mixing region of the fuel and oxidizer streams. On the other hand, the temperature in the inner region upstream was low. The burnt gas generated upstream mixed with the unburnt gas, resulting in the generation of the hightemperature zone downstream. In contrast, the temperature as determined using the FPV model was slightly higher. Although the temperature was the highest immediately after the mixing of the fuel and oxidizer streams in the case 
model. This difference results from the omission of the details of the chemical reaction process in the EBU model, as rapid changes in the temperature are one of the basic characteristics of an infinitely fast chemistry. The high-temperature region was distributed sparsely in the broader area relative to that in the EBU odel, indicating that the region where the chemical reactions occur is not limited to the region of mixing of the fuel and oxidizer streams near the burner and that the chemical reactions can occur in all regions of the flame. These results also suggest that a premixed combustion mode may exist even in the case of a nonpremixed fuel supply system.

The measured radial distributions of the gas temperature [3.9, 40] and those calculated using the two models for each axial position are presented in Figure 5 . The temperature determined using the EBU model differs from that for the FPV model at $x / R=0.89$. Specifically, the numerical solutions obtained using the EBU model underpredicted the temperature at the center and overpredicted that in the mixing region of the fuel and oxidizer streams. In addition, the chemical reactions finish early upstream, and the gas temperature increases rapidly in the mixing region. On the other hand, the FPV model could capture the temperature increase at the center with higher accuracy than the EBU model at $x / R=0.89$ and 1.57 . In the downstream, for $x / R=4.52$ and 5.2 , the differences between the results obtained using the EBU and FPV models were smaller, and the results were in reasonable agreement with the experimental data. 


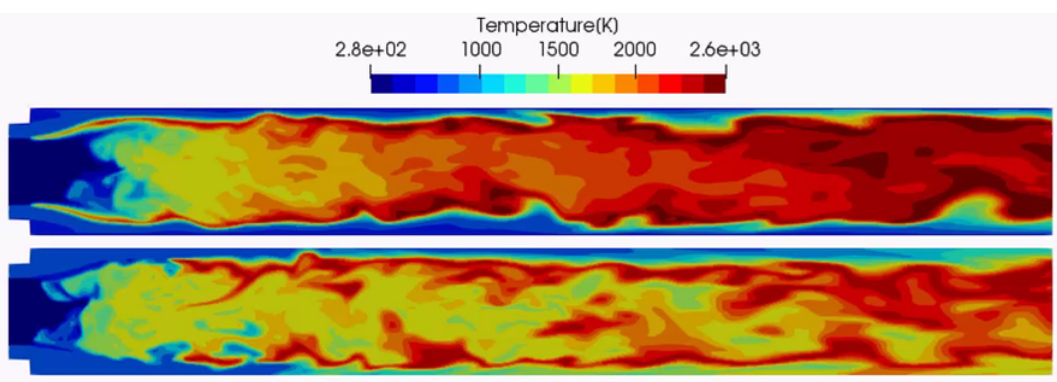

Figure 4: Snapshots of temperature distributions at $0.4 \mathrm{~s}$ (top: EBU model, bottom: FPV model).

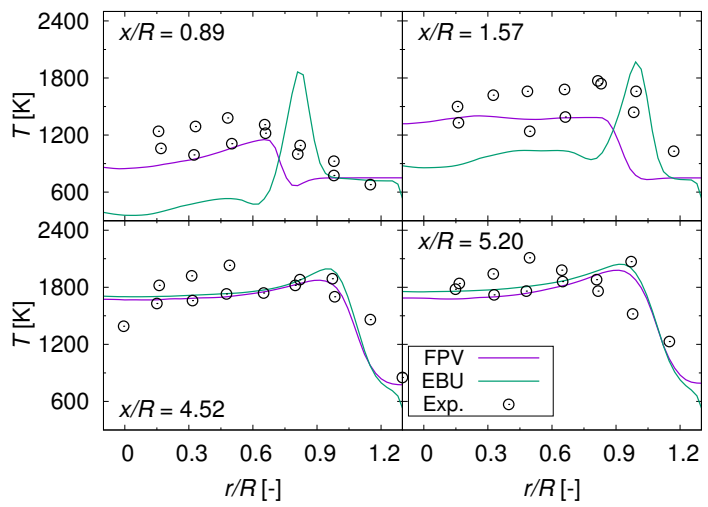

Figure 5: Radial distributions of measured time-mean temperatures[39, 40] and those calculated using EBU and FPV models.

Figure shows snapshots of the mixture fraction distributions. The fuel gas flowed into the combustor for a while and spread along the radial direction. As the inlet is at a distance from the region where the mixture fraction begins to decrease, it was confirmed that the mixing of the fuel and oxidizer streams was not promoted significantly in the EBU model. This result suggests that the chemical reactions progress only in the mixing region of the fuel and oxidizer streams and not in the inner region upstream. In contrast, in the FPV model, the mixture fraction is already lower further upstream owing to the promotion of the mixing of the fuel and oxidant. This promotes the chemical reactions in 
the inner region as compared to the case for the EBU model. Figure $\square$ shows the radial distributions of the measured [39, 40] and calculated time-mean mixture fractions. At $x / R=0.21$, the values determined using the combustion models were higher than the experimental data, especially at the center of the combustor because a parabolic distribution was used for the boundary conditions of the axial velocity. If the advanced inlet conditions, including the turbulent fluctuations, were to be used as the boundary conditions, mixing would be promoted to a greater degree near the burner, leading to earlier ignition at the center of the combustor. Another reason may be the fact that the sampling position along the line of $x / R=0.21$ is located immediately downstream of the burner, resulting in experimental variations and hence differences between the numerical solutions and the experimental data. In fact, as shown later, the root mean square (RMS) axial velocity was not very high near the burner. In the other regions, the solution obtained using the FPV model was in keeping with the experimental data while the EBU model still significantly overpredicted the values. These results suggest that the combustion model used determines the combustion region based on the calculated density and viscosity.

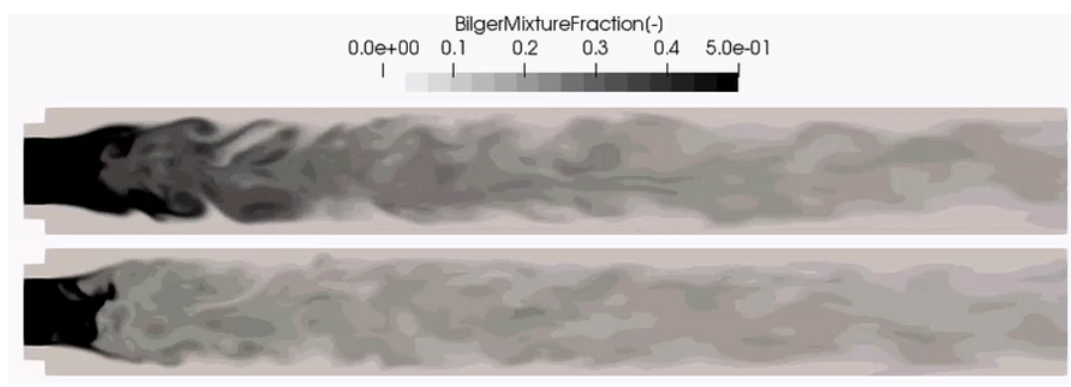

Figure 6: Snapshots of mixture fraction distributions at $0.4 \mathrm{~s}$ (top: EBU model, bottom: FPV model). Maximum value of mixture fraction was set to 0.5 . 


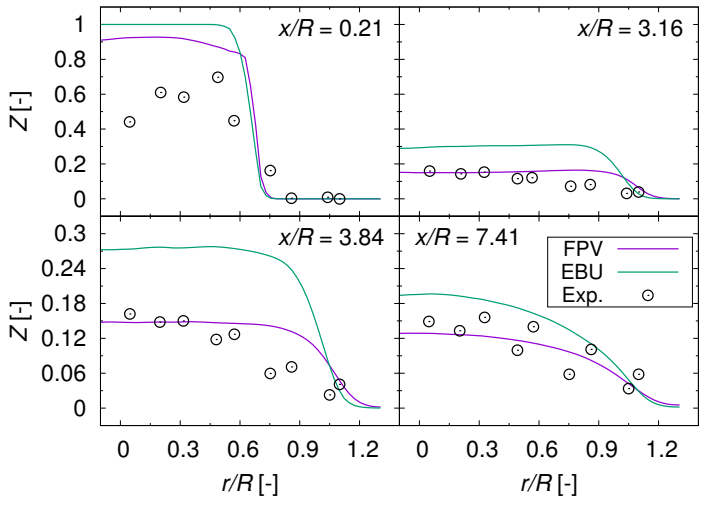

Figure 7: Radial distributions of time-mean mixture fractions as measured [39, 40] and calculated using EBU and FPV models.

\subsection{Velocity and chemical species} culation flows were generated at the center and near the wall of the combustor by the relatively high-velocity oxidizer stream. In particular, the internal recirculation zone at the center of the combustor is a characteristic of this domain and contributed to flame stabilization. The magnitude of the negative velocity in the internal recirculation zone as predicted by the EBU model was smaller than that for the FPV model. Because of the smaller velocity, the settled position of the recirculation zone moved slightly downstream in the EBU model. The chemical reactions occurred in the mixing region of the fuel and oxidizer streams, and the expansion energy generated by the sudden change in the denaxial velocity of the oxidizer stream was slightly higher than that in the case of the FPV model, as shown in Figure $\mathbf{8}$. Figure $\mathbf{9}$ shows the radial distribution of the time-mean and RMS axial velocities. Although both combustion models yielded results that were in keeping with the experimental data, they could not reproduce the axial velocity distributions near the center at $x / R=1.27$ and 4.67. Specifically, the models overpredicted the axial velocity at $x / R=1.27$ and underpredicted it at $x / R=4.67$. Owing to these discrepancies, the simula- 
tion could not predict the exact position of the internal recirculation zone with high accuracy. In addition, it was confirmed that the velocity predicted using the EBU model for the radial interval of $0.6<r / R<0.9$ was slightly higher, as stated earlier.

In the numerical solutions, two peaks were observed in the RMS velocity distribution at the first three sampling lines from the inlet. Although these peaks were not very distinct in the experimental data, they are acceptable because they were located at the boundary between the fuel and oxidizer streams and that between the oxidizer stream and the external recirculation flow near the wall. A relatively large difference comparable to the time-mean velocity at $x / R=4.67$ was not observed between the measured and calculated RMS velocities.

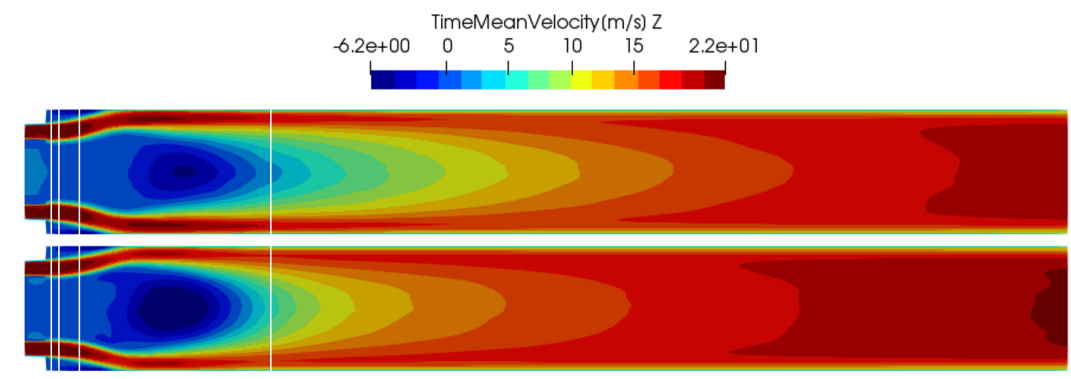

Figure 8: Time-mean axial velocity distribution (top: EBU model, bottom: FPV model). White lines correspond to sampling positions at $x / R=0.14,0.38,1.27$, and 4.67 , respectively. 


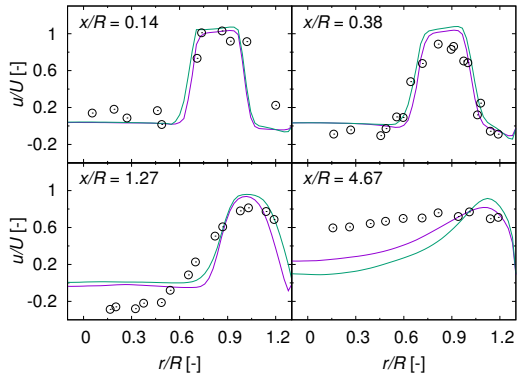

(a) Time-mean velocity

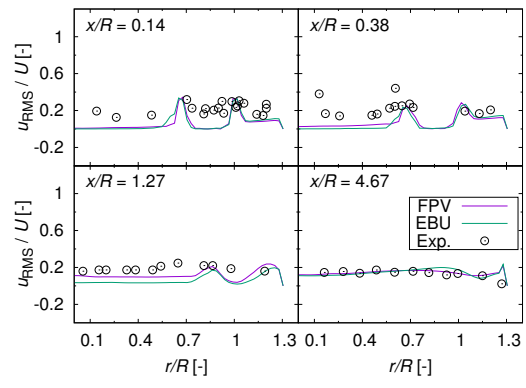

(b) RMS velocity

Figure 9: Radial distributions of time-mean and RMS axial velocities calculated using each combustion model. Experimental values were taken from previous works [39, 40]].

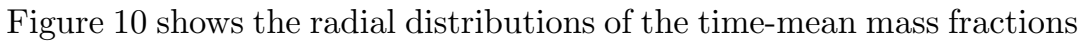
of the combustion products and $\mathrm{CO}$. The sum of the mass fractions of $\mathrm{H}_{2} \mathrm{O}$ and $\mathrm{CO}_{2}$ was taken as the products. Note that the numerical solution obtained using the EBU model is not shown in Figure $\mathbf{0}$ (b) because the global reaction for complete combustion, which does not involve the intermediate products formed during the combustion process, was used for the simulation performed using the EBU model. Both combustion models underestimated the mass fractions of the products at the center at $x / R=0.21$ owing to the inlet conditions used in this study, as described earlier. If mixing occurs readily after the injection of the two streams owing to velocity fluctuations, the chemical reactions will commence earlier. In this case, the chemical products will be generated even at $x / R=0.21$. Moving to the outer region, which corresponds to the mixing region of the fuel and oxidizer streams, the mass fraction as determined using the EBU model increased rapidly and reached a much higher value than that determined experimentally. It can be argued that the reaction rate determined using the EBU model was too high and the assumption of an infinitely fast chemistry would not be valid in this domain. The EBU model also overestimated the reaction rate downstream. In contrast, there was no sudden increase in the reaction rate in the case of the FPV model because the chemical reactions 
progressed slowly and as per the actual chemical kinetics. Apart from the most upstream region, which is sensitive to the inlet boundary conditions, in general, the numerical solutions obtained using this model were in agreement with the experimental data. The high accuracy of the FPV model is evident from the CO mass fractions shown in Figure प0 (b).

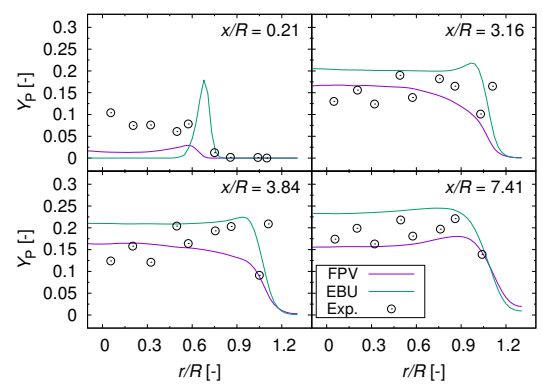

(a) Products $\left(\mathrm{CO}_{2}\right.$ and $\left.\mathrm{H}_{2} \mathrm{O}\right)$

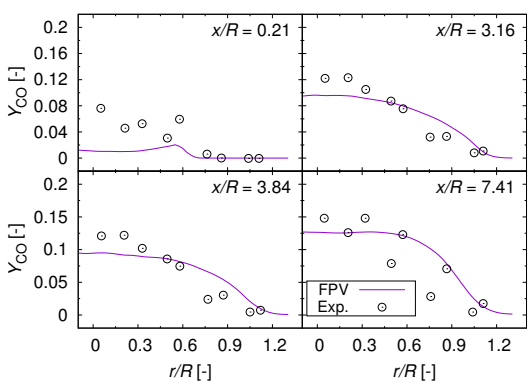

(b) $\mathrm{CO}$

Figure 10: Radial distributions of time-mean mass fractions of products and CO calculated using each reaction model. Experimental values were taken from previous works [39, 40].

\subsection{Analysis of flame structure based on numerical results obtained using FPV} model

To gain insights into the characteristics of the combustion model, the local combustion modes were assessed using the flame index [61], which was calculated from the following equation:

$$
F . I .=\nabla \tilde{Y}_{\mathrm{CH}_{4}} \cdot \nabla \tilde{Y}_{\mathrm{O}_{2}}
$$

where the fuel and oxidizer are $\mathrm{CH}_{4}$ and $\mathrm{O}_{2}$, respectively. As the flame index can be calculated with ease, a number of previous studies have used it as an indicator of the local combustion mode $[62-66]$. The flame index identifies the premixed and diffusion combustion regions based on the gradients in the fuel and oxidizer concentrations. When the fuel and oxidizer move in the same direction, that is, when the flame index is positive, the combustion mode is the premixed type. On the other hand, in the opposite case, it is the diffusion type. 
In this study, the flame index was normalized to range from zero to unity. Thus,

and the chemical reactions occur in the nonpremixed combustion mode. The internal recirculation flow at the center of the combustor transports the unburnt oxidant into the fuel stream, resulting in premixed combustion within the flame. The burnt gas with a high temperature is also transported upstream, resulting 355

combustion mode is determined by the flow field and that the premixed and diffusion modes coexist in the combustor. This is also the reason the EBU model was unable to capture the small changes in the temperature and chemical species during the LES. 

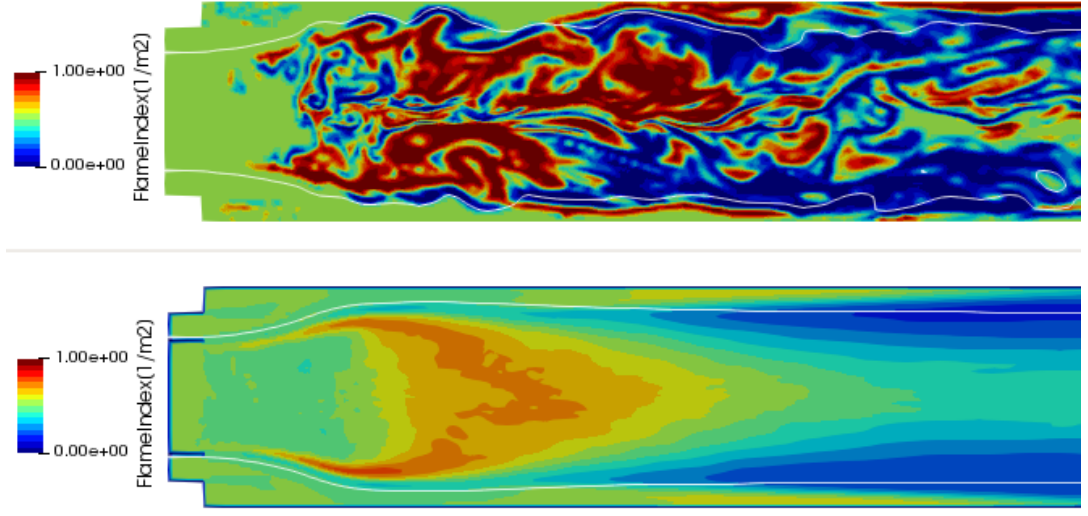

Figure 11: Snapshots of normalized flame index distributions (top: instantaneous at 1.5 $\mathrm{s}$, bottom: time mean). White lines are contour lines for stoichiometric mixture fraction, $Z_{s t}=0.0552$.
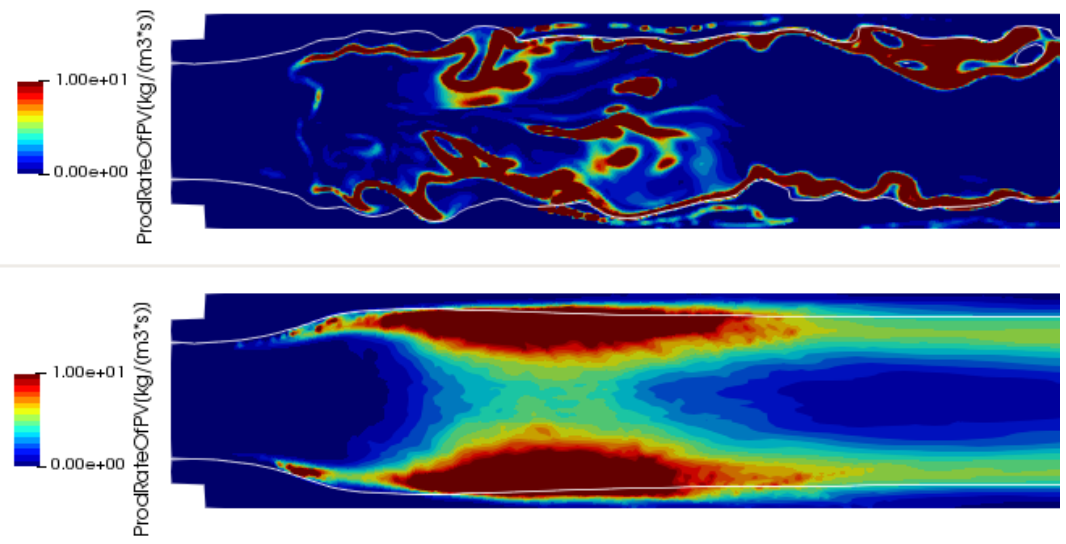

Figure 12: Snapshots of production rate of progress variable (top: instantaneous at $1.5 \mathrm{~s}$, bottom: time mean). White lines are contour lines for stoichiometric mixture fraction, $Z_{s t}=$ 0.0552. Elapsed time for instantaneous distribution is same as that in Figure $\square$. In addition, maximum values of color bar have been clipped at $10 \mathrm{~kg} /\left(\mathrm{m}^{3} \cdot \mathrm{s}\right)$. 


\subsection{Computational cost}

Figure [3 shows the histories of timesteps in the EBU and FPV models. In

365 than that in the EBU model. Table $\square$ shows the comparison of the computational costs of the EBU and FPV models. The computational time in the FPV model was approximately 2.5 times longer than that in the EBU model even though the number of governing equations was smaller in the FPV model. As shown sparsely in the broader area relative to that in the EBU model, and the number of iterations also increased until the governing equations converged. Therefore, it can be concluded that the combustion model should be selected based on the required simulation accuracy and the computational cost.

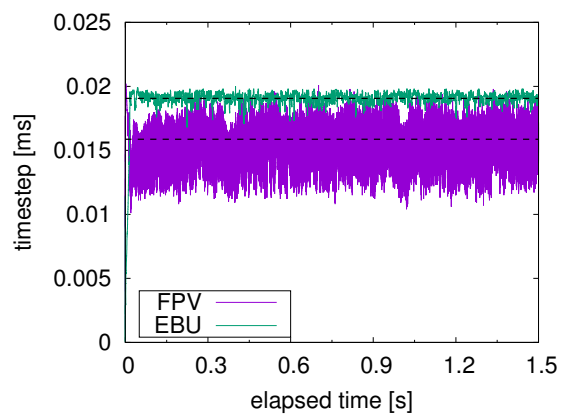

Figure 13: Histories of timesteps in the EBU and FPV models. The dotted lines are averaged values between $0.5-1.5 \mathrm{~s}$.

Table 2: Comparison of the computational costs of the EBU and FPV models.

\begin{tabular}{lcc}
\hline & FPV & EBU \\
\hline number of steps & 95121 & 80041 \\
computational time & approx. 432 hours & approx. 168 hours \\
averaged timestep in 0.5-1.5 s & $1.59 \times 10^{-5} \mathrm{~s}$ & $1.91 \times 10^{-5} \mathrm{~s}$ \\
standard deviations in 0.5-1.5 s & $1.31 \times 10^{-6} \mathrm{~s}$ & $3.64 \times 10^{-7} \mathrm{~s}$ \\
\hline
\end{tabular}




\section{Conclusions}

The characteristics of the EBU and FPV models were investigated through an LES of a coaxial diffusion flame. In the EBU model, which was constructed based on an assumption of an infinitely fast chemistry, the chemical reactions occur only in the mixing region of the fuel and oxidizer streams, and the temperature and mass fractions of the formed products were overestimated in this region. On the other hand, the FPV model could approximate the experimental data because the look-up tables used in this model include detailed information regarding the chemical kinetics. The positions of the internal recirculation zone in the EBU and FPV models were also different, suggesting that the combustion model used has a significant effect on the flow fields based on the fluid properties. Furthermore, the flame index, which is an indicator of the local combustion mode, suggested that the premixed and diffusion modes coexist in the investigated combustor. The internal recirculation flow would result in complex mixing behaviors within the combustor and contribute to the formation of a premixed combustion region. Given these characteristics of an infinitely fast chemistry, it can be concluded that the appropriate combustion model should be selected based on the required simulation accuracy and computational cost.

\section{Acknowledgments}

This work was supported by the Japan Society for the Promotion of Science (JSPS) [grant number JP18K03964], the Tonen General Sekiyu Research/Development Encouragement \& Scholarship Foundation, and the "Leading Young Researcher Overseas Visit Program” of Tohoku University. Support was also provided by a JSPS Grant-in-Aid for Research Fellows [grant number 18J11135].

\section{References}

[1] J. A. Wünning, J. G. Wünning, Flameless oxidation to reduce thermal noformation, Prog. Energy Combust. Sci. 23 (1) (1997) 81-94. http://dx. doi.org/10.1016/S0360-1285(97)00006-3 
[2] A. Cavaliere, M. de Joannon, Mild Combustion, Prog. Energy Combust. Sci. 30 (4) (2004) 329-366. http://dx.doi.org/10.1016/j.pecs.2004. 02.003

[3] O. Lammel, H. Schütz, G. Schmitz, R. Lückerath, M. Stöhr, B. Noll, M. Aigner, M. Hase, W. Krebs, FLOX(R) Combustion at High Power Density and High Flame Temperatures, J. Eng. Gas Turb. Power 132 (12) (2010) 121503-121510, 10.1115/1.4001825. http://dx.doi.org/10.1115/ 1.4001825

[4] C. Zamfirescu, I. Dincer, Ammonia as a green fuel and hydrogen source for vehicular applications, Fuel Process. Technol. 90 (5) (2009) 729-737. http://dx.doi.org/10.1016/j.fuproc.2009.02.004

[5] B. J. P. Buhre, L. K. Elliott, C. D. Sheng, R. P. Gupta, T. F. Wall, Oxy-tuel combustion technology for coal-fired power generation, Prog. Energy Combust. Sci. 31 (4) (2005) 283-307. http://dx.doi.org/10.1016/j.pecs. 2005.07 .001

[6] T. Wall, Y. Liu, C. Spero, L. Elliott, S. Khare, R. Rathnam, F. Zeenathal, B. Moghtaderi, B. Buhre, C. Sheng, R. Gupta, T. Yamada, K. Makino, J. Yu, An overview on oxyfuel coal combustion-State of the art research and technology development, Chem. Eng. Res. Des. 87 (8) (2009) 10031016. http://dx.doi.org/10.1016/j.cherd.2009.02.005

[7] P. Pradhan, S. M. Mahajani, A. Arora, Production and utilization of fuel pellets trom biomass: A review, Fuel Process. Technol. 181 (2018) 215-232. http://dx.doi.org/10.1016/j.fuproc.2018.09.021

[8] C. Yin, L. Rosendahl, S. K. Kær, Towards a better understanding of biomass suspension co-firing impacts via investigating a coal flame and a biomass Hame in a swirl-stabilized burner tlow reactor under same conditions, Fuel Process. Technol. 98 (2012) 65-73. http://dx.doi.org/10. $1016 / j . f u p r o c .2012 .01 .024$ 
[9] P. J. Coelho, N. Peters, Numerical simulation of a mild combustion burner, Combust. Flame 124 (3) (2001) 503-518. http://dx.doi.org/10.1016/ S0010-2180(00)00206-6

[10] P. Kumar, T. R. Meyer, Experimental and modeling study of chemicalkinetics mechanisms for $\mathrm{H} 2-\mathrm{NH} 3$-air mixtures in laminar premixed jet Hames, Fuel 108 (2013) 166-176. http://dx.doi.org/10.1016/j.fuel. 2012.06 .103

[11] L. Chen, S. Z. Yong, A. F. Ghoniem, Oxy-fuel combustion of pulverized coal: Characterization, fundamentals, stabilization and CFD modeling, Prog. Energy Combust. Sci. 38 (2) (2012) 156-214. http://dx.doi.org/ $10.1016 / j \cdot$ pecs.2011.09.003

[12] T. Maffei, R. Khatami, S. Pierucci, T. Faravelli, E. Ranzi, Y. A. Levendis, Experimental and modeling study of single coal particle combustion in O2/N2 and Oxy-fuel (O2/CO2) atmospheres, Combust. Flame 160 (11) (2013) 2559-2572. http://dx.doi.org/10.1016/j.combustflame.2013. 06.002

[13] S. Zhou, T. Hosseini, X. Zhang, N. Haque, L. Zhang, Selective removal of sodium and calcium from low-rank coal - Process integration, simulation and techno-economic evaluation, Fuel Process. Technol. 172 (2018) 13-28. https://doi.org/10.1016/j.fuproc.2017.11.028

[14] M. Issac, A. De Girolamo, B. Dai, T. Hosseini, L. Zhang, Intluence of biomass blends on the particle temperature and burnout characteristics during oxy-fuel co-combustion of coal, Journal of the Energy Institute (2019) In press. https://doi.org/10.1016/j.joei.2019.04.014

[15] R. Kurose, H. Makino, A. Suzuki, Numerical analysis of pulverized coal combustion characteristics using advanced low-NOx burner, Fuel 83 (6) (2004) 693-703. http://dx.doi.org/10.1016/j.fuel.2003.07.003 
[16] M. Muto, Prediction of NOx Formation in Pulverized Coal Combustion Fields Using Large-eddy Simulation - Application to Multi-scale Combustion Fields -, J. Soc. Powder Technol. Jpn. 52 (11) (2015) 658-662. http://dx.doi.org/10.4164/sptj.52.658

[17] K. Xu, Y. Wu, H. Shen, Q. Zhang, H. Zhang, Predictions of soot formation and its effect on the Hame temperature of a pulverized coal-air turbulent jet, Fuel 194 (2017) 297-305. http://dx.doi.org/10.1016/j.fuel.2017.01. 032

[18] M. Muto, K. Yuasa, R. Kurose, Numerical simulation of soot formation in pulverized coal combustion with detailed chemical reaction mechanism, Adv. Powder Technol. 29 (5) (2018) 1119-1127. http://dx.doi.org/10. $1016 / j$. apt.2018.02.002

[19] I. I. Enagi, K. A. Al-attab, Z. A. Zainal, Combustion chamber design and performance for micro gas turbine application, Fuel Process. Technol. 166 (2017) 258-268. http://dx.doi.org/10.1016/j.fuproc.2017.05.037

[20] D. Perrone, T. Castiglione, A. Klimanek, P. Morrone, M. Amelio, Numerical simulations on Oxy-MILD combustion of pulverized coal in an industrial hoiler, Fuel Process. Technol. 181 (2018) 361-374. http://dx.doi. org/10.1016/j.fuproc.2018.09.001

[21] D. B. Spalding, Mixing and chemical reaction in steady confined turbulent Hlames, Symp. (Int.) Combust. 13 (1) (1971) 649-657. http://dx.doi.org/ $10.1016 / \mathrm{S} 0082-0784(71) 80067-\mathrm{X}$

[22] F. C. Lockwood, The modelling of turbulent premixed and dittusion combustion in the computation of engineering Hows, Combust. Flame 29 (1977) 111-122. http://dx.doi.org/10.1016/0010-2180(77)90101-8

[23] B. F. Magnussen, B. H. Hjertager, On mathematical modeling of turbulent combustion with special emphasis on soot formation and combustion, 
[31] F. A.Williams, Combustion Theory, 2nd Edition, CRC Press, Boca Raton, 1985. http://dx.doi.org/10.1201/9780429494055

Symp. (Int.) Combust. 16 (1) (1977) 719-729. http://dx.doi.org/10. 1016/S0082-0784(77)80366-4

[24] L. Y. Hu, L. X. Zhou, J. Zhang, Large-Eddy Simulation of a Swirling Diffusion Flame Using a SOM SGS Combustion Model, Numer. Heat Tr. B: Fund. 50 (1) (2006) 41-58. http://dx.doi.org/10.1080/ $1040 r / 90500459395$

[25] ANSYS Mechanical APDL Theory Reference, Release 15.0 (2013).

[26] P. E. DesJardin, S. H. Frankel, Large eddy simulation of a nonpremixed reacting jet: Application and assessment of subgrid-scale combustion models, Physics of Fluids 10 (9) (1998) 2298-2314. http://dx.doi.org/10. $1063 / 1.869749$

[27] M. Muto, H. Watanabe, R. Kurose, S. Komori, S. Balusamy, S. Hochgreb, Large-eddy simulation of pulverized coal jet flame - Effect of oxygen concentration on NOx tormation, Fuel 142 (0) (2015) 152-163. http: //dx.doi.org/10.1016/j.fuel.2014.10.069

[28] C. D. PIERCE, P. MOIN, Progress-variable approach for large-eddy simulation of non-premixed turbulent combustion, J. Fluid Mech. 504 (2004) 73-97. http://dx.doi.org/10.1017/S0022112004008213

[29] J. A. van Oijen, F. A. Lammers, L. P. H. de Goey, Modeling of complex premixed burner systems by using flamelet-generated manifolds, Combust. Flame 127 (3) (2001) 2124-2134. http://dx.doi.org/10.1016/ S0010-2180(01)00316-9

[30] J. A. van Oijen, L. P. H. de Goey, Modelling of premixed counterflow Hlames using the flamelet-generated manifold method, Combustion Theory and Modelling 6 (3) (2002) 463-478. http://dx.doi.org/10.1088/ $1364-7830 / 6 / 3 / 305$ 
[32] B. Franzelli, B. Fiorina, N. Darabiha, A tabulated chemistry method tor spray combustion, Proc. Combust. Inst. 34 (1) (2013) 1659-1666. http: //dx.doi.org/10.1016/j.proci.2012.06.013

[33] J. Tillou, J. B. Michel, C. Angelberger, D. Veynante, Assessing LES models based on tabulated chemistry for the simulation of Diesel spray combustion, Combust. Flame 161 (2) (2014) 525-540. http://dx.doi.org/10.1016/j. combustf lame.2013.09.006

[34] J. Watanabe, K. Yamamoto, Flamelet model for pulverized coal combustion, Proc. Combust. Inst. 35 (2) (2015) 2315-2322. http://dx.doi.org/ $10.1016 / j \cdot$.proci.2014.07.065

[35] M. Vascellari, H. Xu, C. Hasse, Flamelet modeling of coal particle ignition, Proc. Combust. Inst. 34 (2) (2013) 2445-2452. http://dx.doi.org/10. $1016 / j \cdot$ proci.2012.06.152

[36] O. T. Stein, G. Olenik, A. Kronenburg, F. Cavallo Marincola, B. M. Franchetti, A. M. Kempf, M. Ghiani, M. Vascellari, C. Hasse, Towards Comprehensive Coal Combustion Modelling for LES, Flow, Turbulence and Combustion 90 (4) (2013) 859-884. http://dx.doi.org/10.1007/ s10494-012-9423-y

[37] B. M. Franchetti, F. Cavallo Marincola, S. Navarro-Martinez, A. M. Kempf, Large Eddy simulation of a pulverised coal jet flame, Proc. Combust. Inst. 34 (2) (2013) 2419-2426. http://dx.doi.org/10.1016/j.proci.2012. 01.056

535 [38] M. Rabaçal, B. M. Franchetti, F. C. Marincola, F. Proch, M. Costa, C. Hasse, A. M. Kempf, Large Eddy Simulation of coal combustion in a large-scale laboratory turnace, Proc. Combust. Inst. 35 (3) (2015) 36093617. http://dx.doi.org/10.1016/j.proci.2014.06.023

[39] F. K.Owen, L. J. Spadaccini, C. T. Bowman, Pollutant formation and energy release in confined turbulent diftusion Hames, Symp. (Int.) Combust. 
16 (1) (1977) 105-117. http://dx.doi.org/10.1016/S0082-0784(77) $80317-2$

[40] F. K. Owen, Laser Velocimeter Measurement of a Contined Turbulent Diffusion Flame Burner (1976). http://dx.doi.org/10.2514/5. 9781600865275.0373 .0394

[41] H. Werner, H. Wengle, Large-Eddy Simulation of 'Turbulent Flow Over and Around a Cube in a Plate Channel, Springer Berlin Heidelberg, Berlin, Heidelberg, 1993, pp. 155-168. http://dx.doi.org/10.1007/ $978-3-642-7 / 6 / 4-8 \_12$

[42] Y. Matsushita, OUTFLOW BOUNDARY CONDITION IN THE FINITE-V(IUUME ME"THOI) FOR UNSTE:ADY-STATE FLUII) FLOW COMPUTATION WITH VARIABLE DEINSTTY, Computational Thermal Sciences 3 (6) (2014) 531-537. http://dx.doi.org/10.1615/ ComputihermalScien. 2012003330

[43] P. M. Massimo Germano, Ugo Piomelli, W. H. Cabot, A dynamic subgrid - scale eddy viscosity model, Physics of Fluids A: Fluid Dynamics (19891993) 3 (7) (1991) 1760-1765. http://dx.doi.org/10.1063/1.857955

[44] N. Branley, W. P. Jones, Large Eddy simulation of a turbulent nonpremixed Hame, Combust. Flame 127 (1-2) (2001) 1914-1934. http: //dx.doi.org/10.1016/S0010-2180(01)00298-X

[45] Y. Hu, R. Kurose, Large-eddy simulation of turbulent autoigniting hydrogen lifted jet Hame with a multi-regime Hamelet approach, Int. J. Hydrogen Energy 44 (12) (2019) 6313-6324. http://dx.doi.org/10.1016/j. i.jhydene.2019.01.096

[46] E. Abtahizadeh, P. de Goey, J. van Oijen, LFiS of Deltt .let-in-Hot Cotlow burner to investigate the effect of preferential diffusion on autoignition of CH4/H2 flames, Fuel 191 (2017) 36-45. http://dx.doi.org/10.1016/j. tue1.2016.11.054 
[47] U. Egüz, N. Leermakers, B. Somers, P. de Goey, Modeling of PCCl combustion with FGM tabulated chemistry, Fuel 118 (2014) 91-99. http: //dx.doi.org/10.1016/j.fuel.2013.10.073

[48] R. W. Bilger, The structure of turbulent nonpremixed flames, Symp. (Int.) Combust. 22 (1) (1989) 475-488. http://dx.doi.org/10.1016/ S0082-0784(89)80054-2

[49] M. Ihme, H. Pitsch, Prediction of extinction and reignition in nonpremixed turbulent flames using a flamelet/progress variable model: 2. Application in LES of Sandia Hames D) and E, Combust. Flame 155 (1-2) (2008) 90-107. http://dx.doi.org/10.1016/j.combustflame.2008.04.015

[50] G. P. Smith, D. M. Golden, M. Frenklac, N. W. Moriarty, B. Eiteneer, M. Goldenberg, C. T. Bowman, R. K. Hanson, S. Song, W. C. G. Jr., V. V. Lissianski, Z. Qin. GRI-mech 3.0 [online] (accessed on July 22, 2019).

[51] H. Pitsch. A C ++ program package for OD combustion and 1D laminar Hame calculations [online] (accessed on July 22, 2019).

[52] A. Rittler, F. Proch, A. M. Kempf, LES of the Sydney piloted spray flame series with the PFGM/ATF approach and different sub-filter models, Combust. Flame 162 (4) (2015) 1575-1598. http://dx.doi.org/10.1016/j. combust.tlame.2014.11.025

[53] M. Rieth, F. Proch, M. Rabaçal, B. M. Franchetti, F. Cavallo Marincola, A. M. Kempf, Flamelet LES of a semi-industrial pulverized coal furпrace, Combust. Flame 173 (2016) 39-56. http://dx.doi.org/10.1016/ j.combust \pm Lame.2016.07.013

[54] F. Proch, A. M. Kempf, Modeling heat loss effects in the large eddy simulation of a model gas turbine combustor with premixed flamelet generated manifolds, Proc. Combust. Inst. 35 (3) (2015) 3337-3345. http: //dx.doi.org/10.1016/j.proci.2014.07.036 
[55] Y. Matsushita, S. Akaotsu, S. Yokoi, Y. Saito, H. Aoki, An Approximate Method for the Computation of Wall Temperature Using Thermal Equilibrium and Fluid Temperatures from the Enthalpy and Mole Fraction, J. Chem. Eng. Jpn. 50 (2) (2017) 111-114. http://dx.doi.org/10.1252/ jcej.16we176

[56] S. Yokoi, Y. Matsukawa, Y. Saito, Y. Matsushita, H. Aoki, W. Malalasekera, A Modified Boundary Condition of Velocity for Continuity Equation with Non-uniform Density Distribution at Outlet Boundary Plane, J. Chem. Eng. Jpn. 51 (8) (2018) 641-645. http://dx.doi.org/10.1252/ jcej.17we178

[57] P. L. Roe, Some contributions to the modelling of discontinuous Hows, Vol. 22 of Lectures in Applied Mechanics, Springer-Verlag, Berlin, 1985. http://adsabs.harvard.edu/abs/1985ams...conf ..163R

[58] A. A. Amsden, F. H. Harlow, A simplified MAC technique for incompressible Hluid How calculations, Journal of Computational Physics 6 (2) (1970) 322-325. http://dx.doi.org/10.1016/0021-9991(70)90029-X

[59] N. Nomura, A. Fujii, T. Tanaka, O. Marques, K. Nakajima, Algebraic Multigrid Solver Using Coarse Grid Aggregation with Independent Aggregation, IEEE International Parallel and Distributed Processing Symposium Workshops (IPDPSW). http://dx.doi.org/10.1109/IPDPSW. 2018.00170

[60] H. A. v. d. Vorst, Bi-CGSTAB: A Fast and Smoothly Converging Variant of Bi-CG for the Solution of Nonsymmetric Linear Systems, SIAM Journal on Scientific and Statistical Computing 13 (2) (1992) 631-644. http://dx. doi.org/10.1137/0913035

[61] H. Yamashita, M. Shimada, T. Takeno, A numerical study on Hame stability at the transition point of jet diffusion Hlames, Symp. (Int.) Combust. 26 (1) (1996) 27-34. http://dx.doi.org/10.1016/S0082-0784(96) $80196-2$ 
[66] X. Wen, Y. Luo, K. Luo, H. Jin, J. Fan, LES of pulverized coal combustion with a multi-regime flamelet model, Fuel 188 (2017) 661-671. http://dx. doi.org/10.1016/j.fuel.2016.10.070 